\title{
Identification of Volatile Organic Compounds in Extremophilic Bacteria and Their Effective Use in Biocontrol of Postharvest Fungal Phytopathogens
}

\section{OPEN ACCESS}

Edited by:

Florence Fontaine,

Université de Reims Champagne-

Ardenne, France

Reviewed by:

Jorge Poveda,

Public University of Navarre, Spain

Alessandra Di Francesco,

University of Bologna, Italy

*Correspondence:

Miguel Rodríguez

miguelrg@correo.ugr.es

Fernando Martínez-Checa

fmcheca@ugr.es

tThese authors have contributed equally to this work and share first authorship

Specialty section:

This article was submitted to Microbe and Virus Interactions With

Plants,

a section of the journal

Frontiers in Microbiology

Received: 09 September 2021

Accepted: 11 October 2021

Published: 12 November 2021

Citation:

Toral L, Rodríguez $M$

Martínez-Checa F, Montaño A,

Cortés-Delgado A, Smolinska A,

Llamas I and Sampedro I (2021)

Identification of Volatile Organic

Compounds in Extremophilic Bacteria and Their Effective Use in Biocontrol

of Postharvest Fungal

Phytopathogens.

Front. Microbiol. 12:773092.

doi: 10.3389/fmicb.2021.773092
Laura Toral ${ }^{1 \dagger}$, Miguel Rodríguez ${ }^{2,3 * t}$, Fernando Martínez-Checa ${ }^{2,3 *}$, Alfredo Montaño ${ }^{4}$, Amparo Cortés-Delgado ${ }^{4}$, Agnieszka Smolinska ${ }^{5}$, Inmaculada Llamas ${ }^{2,3}$ and Inmaculada Sampedro ${ }^{2,3}$

${ }^{1}$ Xtrem Biotech S.L., European Business Innovation Center, Avenida de la Innovación, Granada, Spain, ${ }^{2}$ Department of Microbiology, Faculty of Pharmacy, Campus de Cartuja s/n, Granada, Spain, ${ }^{3}$ Biomedical Research Center (CIBM), Avenida del Conocimiento s/n, Granada, Spain, ${ }^{4}$ Department of Food Biotechnology, Instituto de la Grasa, Sevilla, Spain,

${ }^{5}$ Department of Pharmacology and Toxicology, Maastricht University, Maastricht, Netherlands

Phytopathogenic fungal growth in postharvest fruits and vegetables is responsible for 20-25\% of production losses. Volatile organic compounds (VOCs) have been gaining importance in the food industry as a safe and ecofriendly alternative to pesticides for combating these phytopathogenic fungi. In this study, we analysed the ability of some VOCs produced by strains of the genera Bacillus, Peribacillus, Pseudomonas, Psychrobacillus and Staphylococcus to inhibit the growth of Alternaria alternata, Botrytis cinerea, Fusarium oxysporum, Fusarium solani, Monilinia fructicola, Monilinia laxa and Sclerotinia sclerotiorum, in vitro and in vivo. We analysed bacterial VOCs by using GC/ MS and 87 volatile compounds were identified, in particular acetoin, acetic acid, 2,3-butanediol, isopentanol, dimethyl disulphide and isopentyl isobutanoate. In vitro growth inhibition assays and in vivo experiments using cherry fruits showed that the best producers of VOCs, Bacillus atrophaeus L193, Bacillus velezensis XT1 and Psychrobacillus vulpis $Z 8$, exhibited the highest antifungal activity against $B$. cinerea, $M$. fructicola and $M$. laxa, which highlights the potential of these strains to control postharvest diseases. Transmission electron microscopy micrographs of bacterial VOC-treated fungi clearly showed antifungal activity which led to an intense degeneration of cellular components of mycelium and cell death.

Keywords: volatile compounds, antifungal activity, biocontrol, fungal phytopathogens, postharvest diseases

\section{INTRODUCTION}

The world population has increased by 1 billion over the last 10 years, reaching a total of 7.8 billion currently, which is expected to rise by a further 1 billion by 2030 . Regardless of environmental damage and potential risks to human health, the use of chemical fertilisers in agriculture and during postharvest storage has increased and remains at high levels 
given the growing demand for food worldwide (Goswami and Deka, 2020). The factors responsible for postharvest losses include fungal pathogen infections which are estimated to account for approximately $20-25 \%$ of fruit and vegetable postharvest decay in developed countries and contribute significantly to a deterioration in quality and nutrient composition, mycotoxin contamination and a reduction in the market value of fruit (Frankowski et al., 2001; Mari et al., 2016; Gotor-Vila et al., 2017; Tozlu et al., 2018). Many fungal species of the most diverse genera have been reported to be associated with postharvest diseases in fruits and vegetables worldwide. These include Penicillium expansum, Penicillium italicum and Penicillium digitatum (Cheng et al., 2020; Kanashiro et al., 2020; Yu et al., 2020; Zhang et al., 2020a), Alternaria alternata (Tozlu et al., 2018; Garganese et al., 2019), Phytophthora citrophthora (Díaz et al., 2020) the necrotrophic pathogens Sclerotinia sclerotiorum and Botrytis cinerea (Fernando et al., 2005; Giorgio et al., 2015; Massawe et al., 2018; Zhao et al., 2020), Colletotrichum gloeosporioides (Jin et al., 2020; Shi et al., 2021), various species belonging to the genus Fusarium (Medina-Romero et al., 2017; Go et al., 2019; Lee et al., 2019) and the genus Monilinia, known to be the most important fungal pathogen to infect stone fruits (Martini and Mari, 2014; Rungjindamai et al., 2014; Obi et al., 2018).

Although postharvest decay has traditionally been controlled through chemical fungicides, their intensive use can cause problems, such as pathogen resistance, pesticide residues, human health hazards and environmental pollution (Mari et al., 2016; Lim et al., 2017). Moreover, due to the toxicological risks involved, chemicals registered for postharvest use are severely limited while consumer awareness of the need for pesticidefree food has been increasing (Gao et al., 2017; Lastochkina et al., 2020). Thus, given their safe, ecofriendly and sustainability properties, biopesticides, which meet the global strategic requirements of organic agriculture, could be a desirable alternative to traditional pesticides (Wu et al., 2019; Zheng et al., 2019).

A wide range of ecological strategies has emerged with the use of anti-phytopathogenic microorganisms and the use of plant-defence hormones or glucosinolates (Poveda, 2020; Poveda et al., 2020). Given the variety of possible fungal inhibition pathways and the wide range of microbial secondary metabolites, postharvest disease management involving biocontrol agents (BCAs) has, in recent years, focused on the use of volatile organic compounds (VOCs; Ryu et al., 2004; Guevara-Avendano et al., 2019). Species of the genera Streptomyces, Pseudomonas, Serratia, Xanthomonas, Alcaligenes, Bacillus and Agrobacterium are reported to be the most frequent producers of these bioactive VOCs (Chaves-Lopez et al., 2015; Schmidt et al., 2015; Asari et al., 2016; Mari et al., 2016; Dias et al., 2017; Gotor-Vila et al., 2017; Lim et al., 2017; Khan et al., 2018).

Microbial volatile organic compounds (MVOCs), which originate from different metabolic pathways during fungal and bacterial growth, contain low molecular weight and high vapour pressure molecules that readily diffuse through water and gas-filled pores in soil environments
(Chaves-Lopez et al., 2015; Parafati et al., 2017; Toffano et al., 2017). From a control perspective, these characteristics expand the area of influence, improve membrane penetration and consequently enhance the lethality of these microorganisms (Logan et al., 2009). Bacterial VOCs inhibit spore germination and mycelial growth of various phytopathogens, promote plant growth and induce plant resistance (Gotor-Vila et al., 2017; Lazazzara et al., 2017; Syed-Ab-Rahman et al., 2019; Di Francesco et al., 2020; Poveda, 2021). However, the composition and antifungal properties of volatiles produced by microorganisms can vary according to the growing medium, oxygen availability, moisture, temperature and $\mathrm{pH}$, as well as the population involved and functional dynamics (Chaves-Lopez et al., 2015; Schmidt et al., 2015). Moreover, MVOCs produced by BCAs can play different regulatory roles in different species, the extent of whose inhibition depends on specific bacteriumfungus interactions (Schmidt et al., 2015; Zheng et al., 2019).

This study thus aims to evaluate the antifungal activity of VOCs produced by bacteria obtained from extreme environments and belonging to the genera Peribacillus, Pseudomonas, Staphylococcus, Psychrobacillus and Bacillus against seven postharvest fruit pathogens. (i) An in vitro approach, together with scanning and transmission microscopy, was used to evaluate the antifungal effect of antipathogenic bacterial VOCs on colony and mycelial growth; (ii) VOCs were identified using headspace solid-phase microextraction coupled with gas chromatographymass spectrometry (HS-SPME-GC/MS); (iii) the effect of pure compounds on the target pathogens was tested in vitro; and (iv) the impact of antifungal activity of bacterial VOCs and synthetic compounds was assayed in vivo on fruits. The impact of the culture medium on VOCs composition and its antifungal activity was also evaluated.

\section{MATERIALS AND METHODS}

\section{Bacterial and Fungal Strains, Growth Media and Culture Conditions}

The bacterial strains used in this study had been isolated from different sources: Peribacillus sp. N3 from river otter (Lutra lutra) faeces and strains Bacillus atrophaeus L193 (Rodriguez et al., 2018), Bacillus velezensis XT1, a patented strain (Béjar et al., 2014), Pseudomonas segetis P6 (Rodriguez et al., 2020b), Psychrobacillus vulpis Z8 (Rodriguez et al., 2020a) and Staphylococcus equorum subsp. equorum EN21 (Vega et al., 2019) from saline and hypersaline environments. We examined the phytopathogenic fungi $A$. alternata CECT 20560, B. cinerea (isolated from Vitis vinifera L. and kindly provided by the Plant Food Research Group, University of Zaragoza, Spain), Fusarium oxysporum CECT 2159, Fusarium solani [isolated from Solanum tuberosum and kindly provided by the Andalusian Agricultural and Fisheries Research and Training Institute (IFAPA), Cordoba, Spain], Monilinia fructicola, Monilinia laxa (both isolated from Prunus persica L. and kindly provided by the Plant Food Research Group, University of Zaragoza, Spain) and S. sclerotiorum CECT 2769. 
Bacillus velezensis strain XT1 was cultured in nutrient broth (NB) medium (No. 3 NutriSelect ${ }^{\circledR}$ Plus, Merck) while the other bacterial strains were cultured in tryptic soy broth (TSB, Panreac ${ }^{\circledR}$ Applichem) at $28^{\circ} \mathrm{C}$ and $120 \mathrm{rpm}$ in a rotary shaker unless otherwise stated. Fungal strains were cultured in potato dextrose agar $\left(\mathrm{PDA}, \mathrm{Difco}^{\circledR}\right)$ medium at $21^{\circ} \mathrm{C}$. To produce bacterial volatile compounds, strains were cultured in tryptic soy agar (TSA, Panreac ${ }^{\circledR}$ Applichem) medium, Schaeffer's growth (SG) medium (Kovacs, 1928) and the medium optimal for lipopeptide production (MOLP; Ahimou et al., 2000). The $\mathrm{pH}$ of each medium was adjusted to 7.2-7.4 using $\mathrm{NaOH} 1 \mathrm{M}$ or $\mathrm{HCl} 1 \mathrm{~N}$.

\section{Gas Chromatography Analysis of Bacterial Volatile Compounds}

The bacterial strains were cultured in flask containing $200 \mathrm{ml}$ of MOLP, SG or TSB for $24 \mathrm{~h}$ at $28^{\circ} \mathrm{C}$ and $120 \mathrm{rpm}$, and the volatile compounds produced were analysed using HS-SPME-GC/MS according to the procedure described by Montaño et al. (2021). Uninoculated MOLP, SG and TSB samples were analysed as controls in order to remove natural occurring volatile compounds from each medium. An aliquot of each sample $(5 \mathrm{ml})$ was inserted into a $15 \mathrm{ml}$ glass vial and $50 \mu \mathrm{l}$ of internal standard (5-nonanol; $2 \mathrm{mg} \mathrm{L}^{-1}$ ) was added. The vial was closed and placed in a water bath adjusted to $40^{\circ} \mathrm{C}$ and stirred at $600 \mathrm{rpm}$ using a stirring bar. After $15 \mathrm{~min}$ of equilibration, the headspace volatile compounds were extracted for $30 \mathrm{~min}$ using a divinylbenzene/carboxen/ polydimethylsiloxane (DVB/CAR/PDMS) fibre $(2 \mathrm{~cm}, 50 / 30 \mu \mathrm{m}$; Supelco, Bellefonte, PA). The volatiles were then desorbed for $15 \mathrm{~min}$ at $265^{\circ} \mathrm{C}$ in a $\mathrm{GC}$ injector port interfaced with a mass detector with a scan range of $\mathrm{m} / \mathrm{z}$ 30-400. Separation was carried out on a VF-WAX MS capillary column $(30 \mathrm{~m} \times 0.25 \mathrm{~mm} \times 0.25 \mu \mathrm{m}$ thickness film) from Agilent Technologies (Santa Clara, CA, United States). The initial oven temperature was $40^{\circ} \mathrm{C}(5 \mathrm{~min})$, followed by $40-195^{\circ} \mathrm{C}$ at $3^{\circ} \mathrm{C}$ $\mathrm{min}^{-1}$ and then held at $195-240^{\circ} \mathrm{C}$ at $10^{\circ} \mathrm{C} \mathrm{min}^{-1}$ for $15 \mathrm{~min}$. Helium was used as the carrier gas at $1 \mathrm{ml} \mathrm{min}^{-1}$ constant flow. Data processing was carried out using MassHunter software (Agilent Technologies). The volatile compounds were initially identified by comparing MS peaks to those in the NIST 17 MS library. The results were then confirmed by comparing the retention indices to literature data reported for equivalent columns and to authentic standards when available. The volatile compounds were quantified by comparison of peak areas to that of internal standard (5-nonanol). All analyses were done in duplicate (i.e., two vials for each bacterial strain).

\section{In vitro Antifungal Activity of Bacterial Volatile Compounds}

The effects of bacterial volatile compounds on the mycelial growth of the fungal phytopathogens $A$. alternata, B. cinerea, F. oxysporum, F. solani, M. fructicola, M. laxa and S. sclerotiorum were assessed using the bi-plate Petri dish method (Lim et al., 2017), as well as MOLP, SG and TSA media to assess bacterial growth. Briefly, $5 \mu$ from an overnight culture $\left(10^{8} \mathrm{CFU} \mathrm{m}{ }^{-1}\right)$ of each bacterial strain in NB or TSB was spotted in the centre of one of the bi-plate compartments. In the other compartment containing the PDA medium, a mycelium plug (Ø $5 \mathrm{~mm}$ ) of each fungus from a 15 day culture was removed using a sterile cork borer and deposited on the agar bi-plates. The plates were immediately sealed with a double layer of Parafilm to prevent volatile leakage and then incubated at $28^{\circ} \mathrm{C}$ for $24 \mathrm{~h}$ followed by incubation at $21^{\circ} \mathrm{C}$ for 15 days. Antifungal activity was measured by the percentage reduction in the mycelial growth with the aid of ImageJ software (Schneider et al., 2012). The experiments were repeated in triplicate using bi-plates with sterile liquid medium instead of bacterial inoculum as control for fungal growth.

\section{In vivo Biocontrol of Fungal Phytopathogens by Bacterial and Synthetic Volatile Compounds}

In vivo antifungal activity of bacterial volatile compounds, together with the main synthetic compounds identified by GC/MS, was analysed in cherry fruits (Prunus avium cv. Picota) according to the protocol described by Gotor-Vila et al. (2017) and Gao et al. (2018), since cherry fruits are the shared host for all fungal pathogens tested. Briefly, cherries were tap-washed and surface-sterilised by spraying with $1 \%(\mathrm{w} / \mathrm{v})$ sodium hypochlorite solution followed by $70 \%(\mathrm{v} / \mathrm{v})$ ethanol and sterile distilled water. Each fruit was wounded using a sterile scalpel, and $10 \mu \mathrm{l}$ of each fungal suspension $\left(10^{6}\right.$ spore $\left.\mathrm{ml}^{-1}\right)$ was deposited. The fruits were placed in $2 \mathrm{~L}(13 \times 13 \times 12 \mathrm{~cm})$ plastic boxes with $20 \mathrm{ml}$ of sterile water-soaked medical gauze $(13 \times 13 \mathrm{~cm})$. Three uncovered Petri dishes containing MOLP medium for each bacterial strain were placed inside the boxes and incubated at $21^{\circ} \mathrm{C}$ for 7 days. The same protocol was used for testing the synthetic volatile compounds acetic acid, acetoin, 2,3-butenodiol, dimethyl disulphide (DMDS), isopentanol and isopentyl isobutanoate using $10 \mathrm{ml}$ glass vials containing $5 \mathrm{ml}$ of a solution of each compound $(50 \mu \mathrm{m})$ in sterile distilled water. Disease incidence and symptom severity were then determined. Experiments were carried out in triplicate using five fruits per replicate; negative controls consisted of a box containing Petri dishes with uncultured media.

\section{Microscopic Analysis of Structural Effects of Volatile Compounds}

Fungal morphology following bacterial VOC treatments (bi-plate method) was studied using a transmission electron microscopy (TEM) high-resolution FEI Titan G2 50-300 microscope equipped with a high angle annular dark field detector. For this purpose, mycelium blocks were cut into $1 \times 1 \mathrm{~mm}$ pieces, fixed with $2.5 \%$ glutaraldehyde in phosphate buffer $(\mathrm{pH} 7.2$ ), dehydrated with an ethanol gradient and embedded in Epon 812 resin. Thin sections $(70 \mathrm{~nm})$ were cut with a diamond knife (Leica, EM UC7, Germany) and stained with $2 \%$ uranyl acetate for $10 \mathrm{~min}$, followed by $3 \%$ lead citrate for $3 \mathrm{~min}$.

Untreated fungal samples were used as negative controls for comparative purposes. 


\section{Statistical Analysis}

The Shapiro-Wilk test was used to verify data normality, and the data were statistically analysed with the aid of the ANOVA $(p \leq 0.05)$ and Tukey tests using SPSS software. In order to detect any groupings of volatile compounds based on the composition of the culture media and the strains, as well as to identify the main components of each group, the data were subjected to principal component analysis (PCA) using SIMCA software version 14.1 (Umetrics, Sweden).

\section{RESULTS}

\section{Characterisation of Bacterial Volatile Compounds Using GC/MS}

The VOCs produced by the six bacterial strains, B. atrophaeus L193, B. velezensis XT1, Peribacillus sp. N3, P. segetis P6, P. vulpis Z8 and $S$. equorum subsp. equorum EN21, grown in $24 \mathrm{~h}$ cultures, were identified and quantified using GC/MS following headspace solid-phase microextraction (HS-SPME). The culture media MOLP, SG and TSA were tested in order to determine the impact of their composition on the production of VOCs and their involvement in antifungal activity. A total of 87 compounds were identified after analysing the uninoculated sterile media and each strain culture in all media (Supplementary Table S1). Butanal, methyl acetate and 2-methyl2-butenal compounds, which were found exclusively in MOLP and TSB uninoculated sterile media, were not also detected in the cultured media. The remaining 84 compounds were identified as ketones (21.4\%), esters (21.4\%), alcohols (15.5\%), carboxylic acids $(11.9 \%)$, sulphur compounds (11.9\%), aromatic hydrocarbons $(10.7 \%)$, aldehydes $(4.8 \%)$, halogenated compounds (1.2\%) and terpens (1.2\%).

Principal component analysis was used to detect VOCs clustering and to determine the relationships between the bacterial strains and culture media. The principal components (PCs), which accounted for the largest variations in data points, were extracted in order to better visualise the data structure in a reduced dimension. The overall PCA dataset consisted of a $21 \times 87$ matrix, with rows representing 21 bacterial cultures and uncultured media, as well as columns representing volatile compound concentrations. General PCA (Figure 1) revealed two main components which, as indicated by the score plot, accounted for $32 \%$ of total variance (Figure 1A). 19.1\% of variance was attributable to principal component 1 (PC1), while $12.9 \%$ of variance corresponded to PC2. All culture strains clearly formed a highly correlated group, except for strain $P$. vulpis Z8 cultured in MOLP, SG and TSB media and strain $S$. equorum EN21 cultured in MOLP medium, which were segregated from the main group. The PCA loading plot (Figure 1B) shows that this segregation is mainly associated with the volatile compounds butyl isobutanoate (80), isopentyl isobutanoate (82), methanethiol (60), 2-phenylethyl isobutanoate (87), S-methyl thio-3-methylbutanoate (83), butyl propanoate (79) and ethyl 2-methylbutanoate (75) produced by strain P. vulpis Z8 for PC1, while PC2 was mainly associated with the volatile compounds propanoic acid (29), butyl acetate (33), hexanoic acid (38), octanoic acid (39), acetic acid (24), butanoic acid (27), 2,6-diethyl-pyrazine (35) and acetone (1) produced by strain $S$. equorum EN21 in the MOLP medium. These volatile compounds were mostly or exclusively released from stains $P$. vulpis Z8 and S. equorum EN21 and at very low levels from other strains.

In order to identify the impact of culture media composition on volatile compound production, each bacterial strain was cultured in MOLP, SG and TSB media. Strain B. atrophaeus L193 produced 25, 22 and 25 volatile compounds in MOLP, SG and TSB media, respectively, most of which were ketones and aromatic hydrocarbons. In the case of strain $B$. velezensis $\mathrm{XT} 1$, the 27, 16 and 27 volatile compounds in MOLP, SG and TSB media, respectively, also mainly corresponded to ketones and aromatic hydrocarbons. With regard to strain Peribacillus sp. N3, a total of 37, 20 and 23 compounds were identified in MOLP, SG and TSB media, respectively, most of which were carboxylic acids and ketones. Strain $P$. segetis $\mathrm{P} 6$ produced 21,10 and 21 volatile compounds, mostly ketones, aromatic hydrocarbons and sulphur compounds, in MOLP, SG and TSB media, respectively. In the case of strain $S$. equorum EN21, a total of 28, 18 and 21 volatile compounds, mostly alcohols, carboxylic acids and aromatic hydrocarbons, were detected in MOLP, SG and TSB media, respectively. Finally, with regard to strain P. vulpis Z8, a total of 40, 22 and 29 compounds, for the most part esters and sulphur compounds, were identified in MOLP, SG and TSB cultures, respectively.

The main volatile compounds produced by each strain were then selected on the basis of two criteria: their absence from uncultured media and a 2 -fold increase in their concentrations in uncultured media. The volatile compounds selected are shown in Table 1. High levels of acetoin and 2,3-butanediol were produced by strains $B$. atrophaeus L193 and B. velezensis XT1. Acetoin was synthesised in all media, with particularly high levels of production in MOLP, while 2,3-butanediol was only detected in MOLP cultures. Acetic acid was the principal volatile compound detected when strains Peribacillus sp. N3 and S. equorum EN21 were cultured in MOLP and SG media. High levels of isopentanol were also produced by $S$. equorum EN21 culture in all media, especially TSB. DMDS was the main volatile compound produced by strain $P$. segetis P6 when cultured in SG medium, as well as by strain P. vulpis Z8 when cultured in all media. High concentrations of isopentyl isobutanoate were only detected when strain P. vulpis Z8 was cultured in all media.

Principal component analysis based on intraspecific differences in medium composition showed a distribution very similar to that previously obtained even though a higher level of correlation was observed for PC1 and PC2 in each medium (Supplementary Figure S1).

\section{In vitro Antifungal Activity of Bacterial Volatile Compounds}

The effects of VOCs on the mycelial growth of fungal phytopathogens A. alternata, B. cinerea, F. oxysporum, F. solani, 

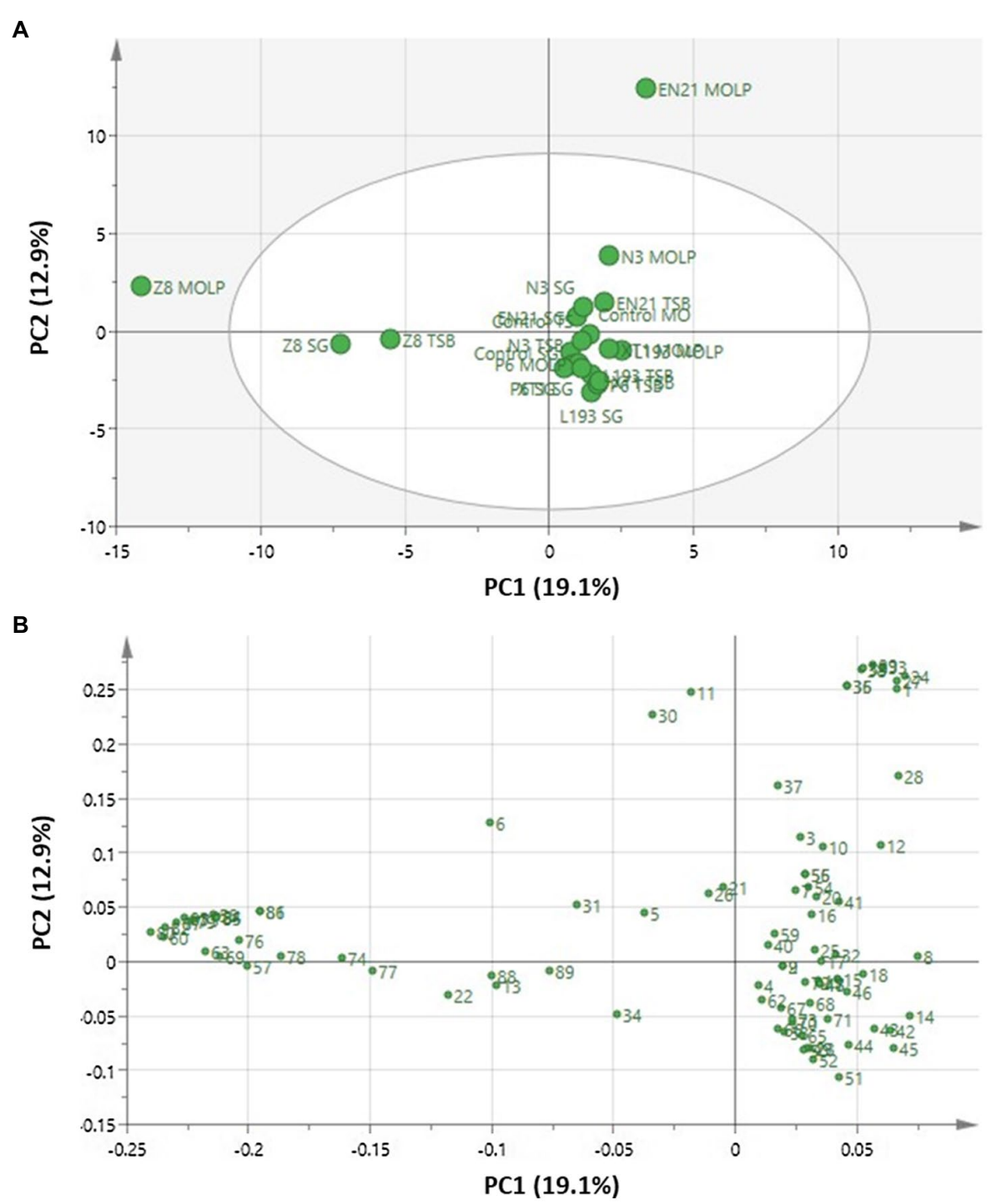

FIGURE 1 | Principal component analysis of volatile compounds obtained using HS-SPME and identified with the aid of GC/MS in B. atrophaeus L193 (L193), B. velezensis XT1 (XT1), Peribacillus sp. N3 (N3), P. segetis P6 (P6), S. equorum EN21 (EN21) and P. vulpis Z8 (Z8) grown in MOLP, SG and TSB media, as well as in uncultured control media. (A) Score plot. (B) Loading plot. Each volatile compound, which is assigned a reference number, can be seen in Supplementary Table S1.

M. fructicola, M. laxa and S. sclerotiorum were assessed using the bi-plate Petri dish method, in the three-culture media assayed previously for VOC characterisation.

The highest antifungal activity was observed when strains were cultivated in the MOLP medium. Thus, volatile compounds produced by strains $B$. atrophaeus L193, B. velezensis XT1 and $P$. vulpis Z8 synthesised in the MOLP medium greatly inhibited the growth of S. sclerotiorum (82, 96 and 56\%, respectively), M. fructicola (42, 37 and 83\%) and M. laxa (51, 54 and 15\%). With regard to $B$. cinerea plates, $B$. atrophaeus $\mathrm{L} 193$ and $B$. velezensis XT1 produced reductions of 27 and $46 \%$ in fungal growth, respectively, while $P$. vulpis Z8 shows no effect on the mycelial growth of $B$. cinerea (data not shown). Fungal growth inhibition of some bacterial strains cultured in the MOLP medium is shown in Figure 2. By contrast, no inhibition of mycelial growth was detected against $A$. alternata, F. oxysporum and F. solani following exposure to VOCs produced by the bacterial strains.

\section{In vivo Biocontrol of Fungal Phytopathogens by Bacterial Volatile Compounds}

To examine in vivo antifungal activity, VOCs produced by strains B. atrophaeus $\mathrm{L} 193$, B. velezensis XT1 and $P$. vulpis Z8 cultured in the MOLP medium were assayed in cherry fruits, together with some of the principal synthetic volatile compounds characterised by GC/MS. With regard to the 
TABLE 1 | Principal volatile compounds for each strain after culturing in MOLP, SG and TSB media.

\begin{tabular}{|c|c|c|c|c|c|c|c|}
\hline \multirow{2}{*}{ Sample } & \multirow{2}{*}{$\begin{array}{l}\text { Culture } \\
\text { medium }\end{array}$} & \multicolumn{6}{|c|}{ Concentration of principal volatile compounds $\left(\mu \mathrm{gL}^{-1}\right)$} \\
\hline & & Acetoin & Acetic acid & 2,3-butanediol & Isopentanol & $\begin{array}{c}\text { Dimethyl } \\
\text { disulphide }\end{array}$ & $\begin{array}{c}\text { Isopentyl } \\
\text { isobutanoate }\end{array}$ \\
\hline \multirow[t]{3}{*}{ Uninoculated media } & MOLP & - & $3.8(3.0)$ & - & - & - & - \\
\hline & SG & - & - & - & - & - & - \\
\hline & TSA & - & - & - & - & - & - \\
\hline \multirow[t]{3}{*}{ B. atrophaeus L193 } & MOLP & $174.0(10.4)$ & $36.9(7.1)$ & $268.8(23.0)$ & - & - & - \\
\hline & SG & $60.5(15.6)$ & $10.0(6.5)$ & - & - & - & - \\
\hline & TSA & $44.5(0.3)$ & $3.6(1.1)$ & - & - & - & - \\
\hline \multirow[t]{3}{*}{ B. velezensis $\mathrm{XT} 1$} & MOLP & $111.0(8.5)$ & $21.9(0.4)$ & 261.7 (49.3) & - & - & - \\
\hline & SG & $64.0(9.6)$ & $6.1(4.1)$ & - & - & - & - \\
\hline & TSA & $60.0(0.5)$ & $2.1(0.0)$ & - & - & - & - \\
\hline \multirow[t]{3}{*}{ Peribacillus sp. N3 } & MOLP & - & $32.9(4.5)$ & - & $7.7(0.2)$ & - & - \\
\hline & SG & - & $30.8(0.4)$ & - & - & - & - \\
\hline & TSA & - & - & - & - & $5.6(1.8)$ & - \\
\hline \multirow[t]{3}{*}{ P. segetis P6 } & MOLP & - & - & - & - & $3.6(0.3)$ & - \\
\hline & SG & - & - & - & - & $46.1(2.9)$ & - \\
\hline & TSA & - & - & - & $3.1(0.1)$ & - & - \\
\hline \multirow[t]{3}{*}{ P. vulpis Z8 } & MOLP & - & - & - & $6.1(1.1)$ & $88.4(2.7)$ & $82.5(1.3)$ \\
\hline & SG & - & - & - & - & $139.7(1.5)$ & $27.4(1.9)$ \\
\hline & TSA & - & - & - & - & $140.1(4.3)$ & $52.0(1.1)$ \\
\hline S. equorum subsp. & MOLP & - & $180.2(17.1)$ & - & $34.3(2.1)$ & - & - \\
\hline \multirow[t]{2}{*}{ equorum EN21 } & SG & - & $25.6(1.9)$ & - & $73.4(3.5)$ & - & - \\
\hline & TSA & - & $4.1(2.0)$ & - & $110.6(27.7)$ & - & - \\
\hline
\end{tabular}

Concentrations of each volatile compound are expressed as the mean of two determinations, with standard deviation (SD) indicated in parenthesis - concentration not detected or insignificant.

percentage of disease incidence, the pathogen $M$. laxa was susceptible to VOCs produced by the strains $B$. atrophaeus L193 and B. velezensis XT1 (Figure 3). In both cases, the VOCs reduced disease incidence by over $50 \%$ as compared to the control. For its part, no significant antifungal activity against $M$. laxa was produced by $P$. vulpis Z8 VOCs. Similar results were obtained with regard to the synthetic volatile compounds isopentanol and DMDS. A very different scenario was observed for antifungal activity against the pathogen M. fructicola, where VOCs produced by B. atrophaeus L193 had no effect, while $P$. vulpis Z8 completely inhibited this pathogen's growth. The VOCs produced by strain B. velezensis $\mathrm{XT} 1$, and the synthetic compound isopentanol, reduced disease incidence in cherries by $50 \%$ as compared to the infection control, while the pathogen $B$. cinerea was completely inhibited by B. atrophaeus L193 VOCs. Similarly, strains $P$. vulpis $\mathrm{Z} 8$ and $B$. velezensis $\mathrm{XT} 1$ reduced the incidence of $B$. cinerea by 48 and $62 \%$, respectively. By contrast, isopentanol and DMDS showed no antifungal activity against $B$. cinerea. The quantity of spores from all pathogenic fungi on the surface of fruits was small and limited to the wound observed when B. atrophaeus L193, $B$. velezensis $\mathrm{XT} 1$ and $P$. vulpis $\mathrm{Z} 8$ VOCs were tested (Supplementary Figure S2). On the other hand, while isopentanol and DMDS had no effect on disease sporulation of $M$. fructicola or $B$. cinerea, they did have a slight impact on $M$. laxa. The synthetic compounds acetoin, acetic acid, 2,3-butanediol and isopentyl isobutanoate did not reduce the disease incidence or fungal sporulation of any target pathogens.

\section{Microscopic Analysis of Structural Effects of Volatile Compounds}

To identify structural disorders caused by bacterial VOC treatment of the phytopathogenic fungi, hyphae were analysed after a 7 day incubation period using TEM. Micrographs of control fungi show well-organised cell walls, as well as cellular membranes, while organelles, such as endoplasmic reticula, abundant mitochondria, nuclei, and vacuoles, can be clearly observed in most of these micrographs (Figures 4A,D,G). By contrast, while maintaining the cell wall structure, $B$. cinerea hyphae treated with $B$. velezensis XT1 (Figure 4B) and $B$. atrophaeus L193 volatiles (Figure 4C) showed severe cytoplasmic cavitation and vacuolation and no organelles were identified. When $M$. laxa was exposed to $B$. velezensis XT1 (Figure 4E) and B. atrophaeus L193 (Figure 4F) VOCs, the hyphal membrane and cell walls appeared to be thinner and degraded, cytoplasmic content was completely coagulated and no organelles could be identified. These effects were also observed in $M$. fructicola hyphae treated with VOCs produced by the $P$. vulpis $\mathrm{Z} 8$ strain (Figure $\mathbf{4 H}$ ).

\section{DISCUSSION}

Bacteria emit VOCs that can inhibit the growth of specific microbial populations (Larkin and Stokes, 1967; Chaves-Lopez et al., 2015). These VOCs, which are easily degraded and act over long distances (Gao et al., 2017), exhibit major advantages over conventional fungicides. In this study, we examined the diversity of VOCs produced by extremophilic bacteria and 


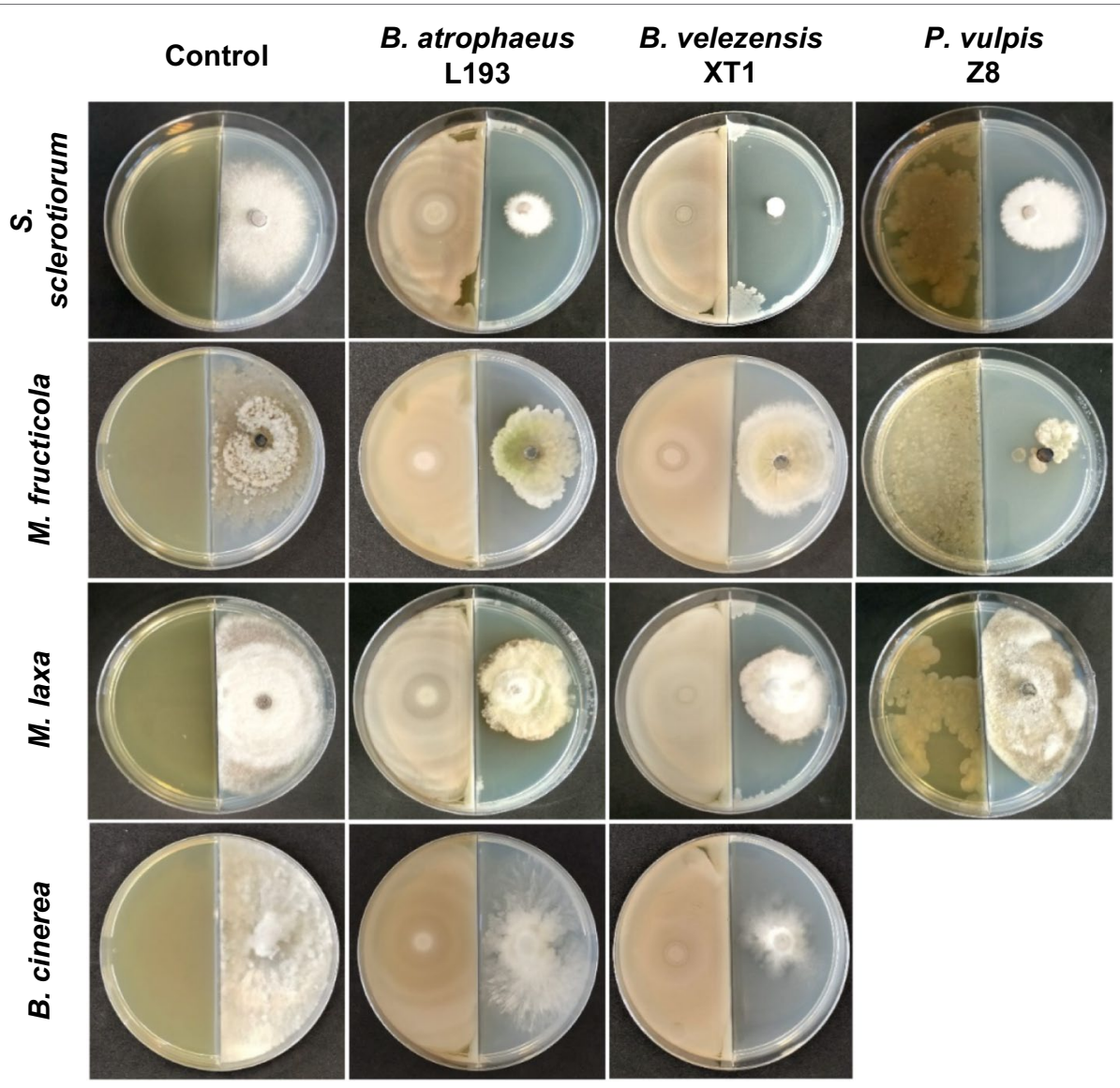

FIGURE 2 | In vitro fungal growth inhibition by bacterial volatile compounds produced by B. atrophaeus L193, B. velezensis XT1 and P. vulpis Z8 when cultured in MOLP medium using the bi-plate method.

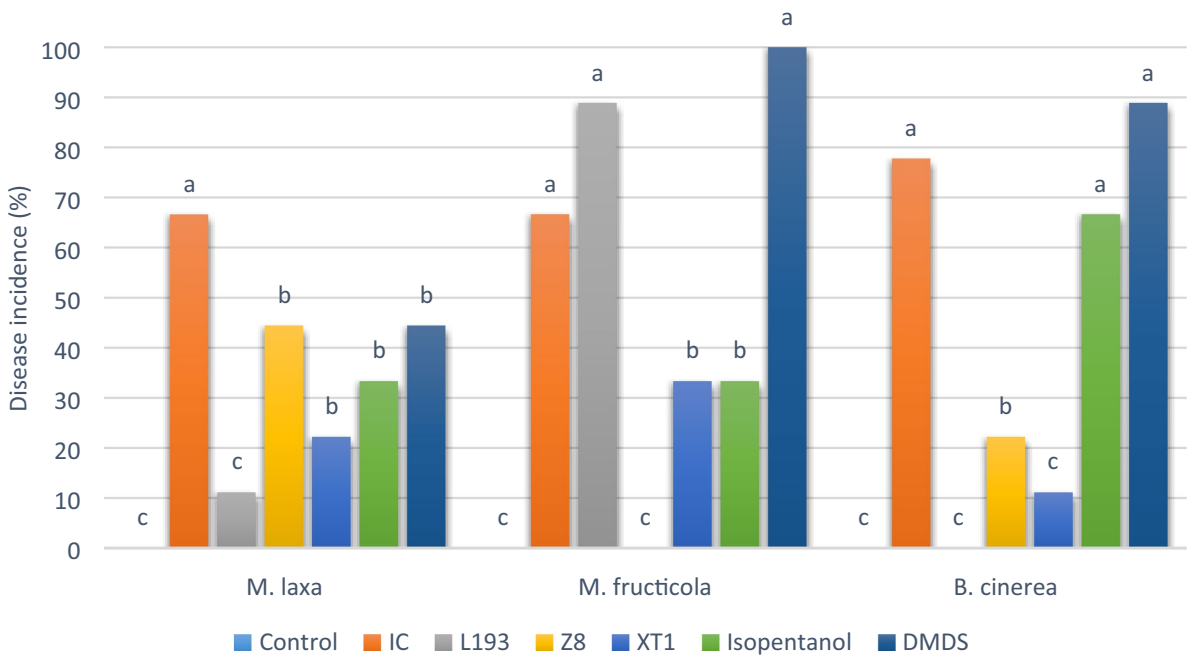

FIGURE 3 | In vivo antagonistic activity of volatile organic compounds (VOCs) from B. atrophaeus L193, B. velezensis XT1 and P. vulpis Z8, as well as the synthetic compounds isopentanol and dimethyl disulphide. The figure shows the disease incidence of cherry fruits artificially inoculated with $M$. laxa, $M$. fructicola and B. cinerea. Control: control treatment without bacterial VOCs or volatile synthetic compounds. IC: pathogen infection control without VOC treatment. Differences between treatments were tested for statistical significance using Chi-squared test: ${ }^{*}(p \leq 0.05),{ }^{* *}(p \leq 0.01),{ }^{* * *}(p \leq 0.001)$ and ns (not significant). 

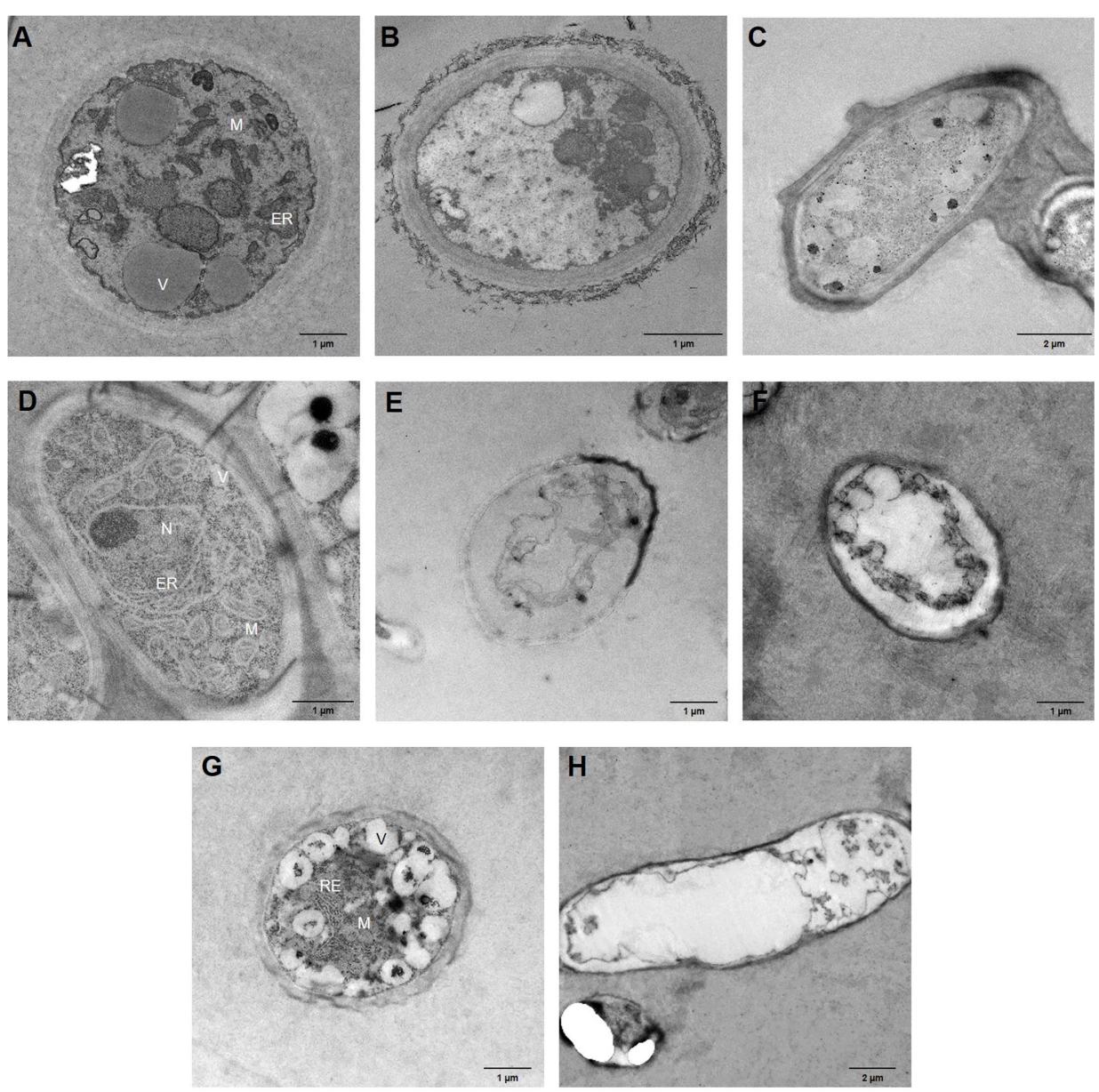

FIGURE 4 | Transmission electron micrographs of fungal hyphae after 7 days of bacterial VOC treatment. (A) Untreated B. cinerea. (B) $B$. cinerea - B. velezensis XT1 strain. (C) B. cinerea - B. atrophaeus L193 strain. (D) Untreated M. laxa. (E) M. laxa - B. velezensis XT1 strain. (F) M. laxa - B. atrophaeus L193 strain.

(G) Untreated M. fructicola. (H) M. fructicola - P. vulpis Z8 strain. ER, endoplasmic reticulum; M, mitochondria; N, nucleus; and V, vacuole.

their antagonistic activity against certain phytopathogenic fungi. Their ability to secrete a wide range of antifungal VOCs could make these bacteria useful in the search for potential biological agents to control postharvest diseases.

Roughly 2,000 compounds produced by almost 1,000 microorganism species are listed in the MVOC database (Lemfack et al., 2018; Caulier et al., 2019). We found acetoin, acetic acid, 2,3-butanediol, isopentanol, dimethylsulfide and isopentyl isobutanoate to be the principal volatile compounds produced by the studied strains.

GC/MS analysis showed that high levels of acetoin and 2,3-butanediol are produced by Bacillus strains. Acetoin, which stimulates induced systemic resistance against Pseudomonas syringae DC3000 (Sierra, 1957) and plant growth (Kai and Piechulla, 2009) and is produced by other Bacillus strains (Asari et al., 2016; Caulier et al., 2019), is synthesised in all media, with particularly high levels detected in MOLP medium, while 2,3-butanediol was exclusively found in MOLP cultures. In addition, the volatile compound 2,3-butanediol is not only known to promote plant growth (Wu et al., 2019) but also to induce modifications in the expression of genes linked to Ralstonia solanacearum and Pectobacterium carotovorum pathogenicity (Marquez-Villavicencio Mdel et al., 2011; Tahir et al., 2017).

The antifungal activity of VOCs has been reported to be associated with functional groups (Sasser, 1990; ChavesLopez et al., 2015). In addition, solute hydrophobicity affects membrane integrity, which is undermined by the application of lipophilic compounds. This may affect DMDS, the principal volatile compound produced by $\mathrm{Z} 8$, and could be responsible for the strong antifungal activity of this bacterium against Monilia sp. and S. sclerotium. The antifungal activity of this volatile compound has been characterised in Bacillus strains (Coosemans, 2005; Caulier et al., 2019) and in Pseudomonas donghuensis against Rhizoctonia solani (Ossowicki et al., 2017; Guevara-Avendano et al., 2019). DMDS, a sulphur-containing compound produced by Pseudomonas sp., also inhibits Phytophthora infestans growth and development (De Vrieze et al., 2015; Guevara-Avendano et al., 2019). 
Acetic acid is the principal volatile compound produced by strains Peribacillus sp. N3 and S. equorum EN21 when cultured in MOLP and SG media. Acetic acid has been found to be an effective antifungal compound in several fruits (BairdParker, 1963; Fuqua et al., 1994), in low concentrations, reduce $B$. cinerea and P. expansum germination to zero (Baird-Parker, 1963) and, at a concentration of $50 \mathrm{~mm}$ significantly inhibit the growth of the phytopathogenic fungus C. gloeosporioides (Kang et al., 2003). The inhibition by this organic acid is closely related to reduced respiration levels rather than to structural cellular damage. Momma et al. (2006) have described how the treatments of soil with acetic acid suppress the survival of $R$. solanacearum.

In addition, high levels of isopentanol were produced by strain S. equorum EN21 in all media, especially in TSB. The antifungal activity of alcohols has been described in previous studies; for example, the phenol 4-chloro-3-methyl has been reported to have a strong antifungal effect on Alternaria solani and B. cinerea (Gao et al., 2017), allyl alcohol inhibits $S$. sclerotiorum germination in bean plants (Lim et al., 2017), while phenylethyl alcohol inhibits the mycelial growth of $P$. italicum (Li et al., 2010).

High concentrations of isopentyl isobutanoate/isobutyrate were only detected when strain $P$. vulpis Z8 was cultured in all media. To the best of our knowledge, no information concerning the antifungal activity of this compound, which could be responsible for the intense antifungal activity of Z8 against $M$. fructicola o $S$. sclerotiorum, existed prior to our study.

A group of highly correlated VOCs was clearly identified for all the strains investigated except for P. vulpis Z8 and $S$. equorum EN21. Several studies have analysed volatile metabolites emitted by clinical Staphylococcus sp. strains (Nasir et al., 2018) but only one has identified antifungal volatile agents produced by Staphylococcus pasteuri against the commercial truffle species Tuber borchii Vittad (Barbieri et al., 2005).

The VOC 2,6-diethyl-pyrazine produced by $S$. equorum strain EN21 is involved in segregating this bacterium from other bacteria. A large proportion of microbial volatiles is pyrazines, which are produced by many strains such Bacillus subtilis and are known to exhibit antifungal activity (Chaves-Lopez et al., 2015; Haidar et al., 2016; Caulier et al., 2019). Some of these compounds affect the sporulation and elongation of $B$. cinerea germ tubes (Chaves-Lopez et al., 2015; Haidar et al., 2016; Caulier et al., 2019), while 2,3,5-trimethylpyrazine antifungal activity against bacterium Fusarium sp. has also been studied (Guevara-Avendano et al., 2019).

The antifungal activity of bacterial volatile compounds tested in vitro demonstrated that strains B. atrophaeus L193, B. velezensis XT1 and $P$. vulpis Z8 cultured in MOLP medium significantly inhibited the growth of $S$. sclerotiorum and M. fructicola. Strains $B$. atrophaeus L193 and B. velezensis XT1 reduced the growth of $M$. laxa and B. cinerea by between 30 and 55\%. Species of the genus Bacillus have been reported to be the most common producers of bioactive VOCs (Chaves-Lopez et al., 2015). The in vitro activity of VOCs against the major phytopathogenic species B. subtilis, Bacillus amyloliquefaciens and B. velezensis has been studied previously (Chaves-Lopez et al., 2015). However, few studies have analysed the volatilome produced by $B$. atrophaeus, and, to the best of our knowledge, this is the first study of the antifungal activity of VOCs produced by the genera Psychrobacillus and Peribacillus.

Our findings show that none of the bacteria tested were effective against all phytopathogenic fungi. Similar results were obtained by Chaves-Lopez et al. (2015) in their study of Bacillus strains. The variations in fungal responses could reflect differences in the sites of action or in the ability of fungi to detoxify the metabolites (Chaves-Lopez et al., 2015). Strains Bacillus and Psychrobacillus, but not B. frigotolerans, showed antifungal activity against major phytopathogens such Monilinia and Sclerotinia.

Previous in vitro studies have demonstrated that VOCs produced by $B$. velezensis inhibit the growth of $B$. cinerea and M. fructicola by over 70\% (Gao et al., 2017; Guevara-Avendano et al., 2019), which is within the 50-97\% range observed in our study of B. velezensis XT1 and B. atrophaeus L193. We found lower levels of antifungal activity against Fusarium for all strains tested, with a $38 \%$ reduction observed following exposure to VOCs produced by $B$. atrophaeus strain L193, which is very similar to the reduction observed for other Bacillus strains (Yuan et al., 2012; Guevara-Avendano et al., 2019). The bacteria which generally showed the most effective antifungal activity, $B$. velezensis XT1 and $B$. atrophaeus $\mathrm{L} 193$, was found to be producers of metabolites with antifungal activity, such as lipopeptides in previous studies (Rodriguez et al., 2018; Toral et al., 2018). Although little is known about VOCs produced by $B$. atrophaeus, the volatilome of $B$. atrophaeus HAB-5 has been identified which has a moderate antifungal effect on the common disease of anthracnose caused by the major fungus C. gloeosporioides (Rajaofera et al., 2019). No information on the antifungal activity of volatile compounds produced by B. atrophaeus against the major phytopathogens analysed existed prior to our study.

The bacterial genus Pseudomonas is also capable of emitting VOCs that inhibit the mycelial growth of $S$. sclerotiorum (Fernando et al., 2005; Guevara-Avendano et al., 2019), although the inhibition rate recorded for P. segetis P6 in this study was very low as compared to the other strains tested. Species of the genus Staphylococcus are mostly known to cause opportunistic human diseases, some of which are frequently found in rhizospheric soil. Although antifungal activity of the bacterium $S$. equorum against $B$. cinerea has been observed (Sadfi-Zouaoui et al., 2008; Reverchon et al., 2019) to our knowledge, the VOCs produced by this bacterium have not previously been described. In our study, the antifungal activity of $S$. equorum strain EN21 against F. solani was found to be very low, with a reduction in fungal growth of only $2 \%$. Reverchon et al. (2019) have shown that VOCs emitted by some Staphylococcus species, which are capable of inhibiting the growth of $F$. solani by over $20 \%$, can, however, increase that of F. oxysporum.

Overall, our results suggest that the antifungal activity of VOCs produced by the extremophilic bacteria studied is dependent on a combination of a limited number of molecules, while the composition of VOC profiles not only depends on species but also on the growing medium (Larkin and Stokes, 1967; 
Chaves-Lopez et al., 2015). The differences in proteins and sugar content in all media reflect differences in the volatilomes produced, whose composition and functional properties are known to be influenced by the growth medium (Asari et al., 2016; Lazazzara et al., 2017). The profiles of VOCs obtained in the present study for different Bacillus strains confirmed the genetic impact on their composition.

Previous studies have shown that bacterial VOCs can affect the hyphal growth, sporulation and spore germination of fungi (Wenke et al., 2010; Asari et al., 2016). Zhou et al. (2019) have suggested that VOCs produced by $B$. subtilis permeabilize fungal spores and inhibit the germination of $M$. fructicola. Other studies have highlighted how the fungal hyphae of $A$. solani are deformed when treated with VOCs produced by $B$. subtilis strains (Zhang et al., 2020b).

The effects of VOCs produced by the strains tested on the morphology of phytopathogens were evaluated using microscopic analysis. TEM micrographs of fungi treated with bacterial VOCs clearly show the impact of antifungal activity, which causes a marked deterioration in cellular components and cell death and inhibits fungal growth and development. Some studies have previously described a similar destruction of fungal structures and cell death induced by VOCs from Pseudomonas spp. strains USB2104 and USB2105, as well as Bacillus sp. USB2103, against S. sclerotiorum (Giorgio et al., 2015), from B. subtilis CF-3 against M. fructicola (Zhou et al., 2019) and by synthetic COVs against B. cinerea (Liu et al., 2016). By contrast, no antifungal activity mediated by VOCs from species of the genus Psychrobacillus was analysed prior to our study.

We investigated the production of several volatile metabolites with different types of biological activity. Previous studies have shown relationships between phytotoxicity and VOCs (Arimura et al., 2010). In some cases, terpenic VOCs inhibited or reduced the germination of seeds of cereals (He et al., 2014). However, exposure of Arabidopsis thaliana of alcoholic VOCs showed non-effect on germination (Lee et al., 2014). These studies highlighted the influence of the origin, dose and application form in the antimicrobial activity of VOCs. In vivo analyses described the potential of VOCs emitted by Bacillus sp. to control postharvest diseases (Zheng et al., 2019). The presence of residual antibiotics produced by these bacteria in fruits constitutes an important health risk because the increased microbial resistance detected in last years (Rashmi et al., 2017). However, VOCs are naturally occurring (emissions by microorganisms) at very low concentrations and do not leave toxic residues on fruit surfaces (Mercier and Smilanick, 2005; Qin et al., 2017). The biological fumigation with VOCs is an

\section{REFERENCES}

Ahimou, F., Jacques, P., and Deleu, M. (2000). Surfactin and iturin A effects on Bacillus subtilis surface hydrophobicity. Enzym. Microb. Technol. 27, 749-754. doi: 10.1016/S0141-0229(00)00295-7

Arimura, G.-I., Shiojiri, K., and Karban, R. (2010). Acquired immunity to herbivory and allelopathy caused by airborne plant emissions. Phytochemistry 71, 1642-1649. doi: 10.1016/j.phytochem.2010.06.021

Asari, S., Matzen, S., Petersen, M. A., Bejai, S., and Meijer, J. (2016). Multiple effects of Bacillus amyloliquefaciens volatile compounds: plant growth promotion interesting strategy to use against a wide range of storage pathogens and fungal decay.

Our search for extremophilic bacteria capable of withstanding stress conditions identified several good candidate strains for postharvest use as VOCs producers. The antifungal activity of many of the VOCs identified in this work has not been previously studied, and further research is required in order to better understand the mechanistic role of VOCs produced by extreme bacteria in antifungal activity to control postharvest diseases.

\section{DATA AVAILABILITY STATEMENT}

The raw data supporting the conclusions of this article will be made available by the authors, without undue reservation.

\section{AUTHOR CONTRIBUTIONS}

LT, MR, FM-C, IL, and IS conceived and supervised the study and designed the experiments. LT, MR, AS, AM, and AC-D performed the experiments and analysed the data. LT, MR, FM-C, and IS prepared the figures, drafted the manuscript, and wrote the final version of the manuscript. All authors contributed to the article and approved the submitted version.

\section{FUNDING}

This research was funded by grants from the Spanish Ministry of the Economy and Competitiveness (PID2019-106704RB-100/ AEI/10.13039/501100011033) and the European Project for Industrial Doctorates 'H2020' (UGR-Ref. 4726).

\section{ACKNOWLEDGMENTS}

The authors thank Michael O'Shea for correcting the English revision of this manuscript.

\section{SUPPLEMENTARY MATERIAL}

The Supplementary Material for this article can be found online at: https://www.frontiersin.org/articles/10.3389/fmicb.2021.773092/ full\#supplementary-material

and growth inhibition of phytopathogens. FEMS Microbiol. Ecol. 92:fiw070. doi: 10.1093/femsec/fiw070

Baird-Parker, A. C. (1963). A classification of micrococci and staphylococci based on physiological and biochemical tests. J. Gen. Microbiol. 30, 409-427. doi: 10.1099/00221287-30-3-409

Barbieri, E., Gioacchini, A. M., Zambonelli, A., Bertini, L., and Stocchi, V. (2005). Determination of microbial volatile organic compounds from Staphylococcus pasteuri against Tuber borchii using solid-phase microextraction and gas chromatography/ion trap mass spectrometry. Rapid Commun. Mass Spectrom. 19, 3411-3415. doi: 10.1002/rcm.2209 
Béjar, V., Llamas, I., Ruíz-García, C., and Quesada, E. (2014). Uso de Bacillus methylotrophicus como estimulante del crecimiento vegetal y medio de control biológico, y cepas aisladas de dicha especie. Patent No PCT/ES2015/070600. Available at: https://patents.google.com/patent/ES2561908A1/es

Caulier, S., Nannan, C., Gillis, A., Licciardi, F., Bragard, C., and Mahillon, J. (2019). Overview of the antimicrobial compounds produced by members of the Bacillus subtilis group. Front. Microbiol. 10:302. doi: 10.3389/ fmicb.2019.00302

Chaves-Lopez, C., Serio, A., Gianotti, A., Sacchetti, G., Ndagijimana, M., Ciccarone, C., et al. (2015). Diversity of food-borne Bacillus volatile compounds and influence on fungal growth. J. Appl. Microbiol. 119, 487-499. doi: 10.1111/jam.12847

Cheng, Y., Lin, Y., Cao, H., and Li, Z. (2020). Citrus postharvest green mold: recent advances in fungal pathogenicity and fruit resistance. Microorganisms 8:449. doi: 10.3390/microorganisms 8030449

Coosemans, J. (2005). Dimethyl Disulphide (DMDS): A Potential Novel Nematicide and Soil Disinfectant. (Leuven, Belgium: International Society for Horticultural Science), 57-64.

De Vrieze, M., Pandey, P., Bucheli, T. D., Varadarajan, A. R., Ahrens, C. H., Weisskopf, L., et al. (2015). Volatile organic compounds from native potatoassociated Pseudomonas as potential anti-oomycete agents. Front. Microbiol. 6:1295. doi: 10.3389/fmicb.2015.01295

Di Francesco, A., Zajc, J., Gunde-Cimerman, N., Aprea, E., Gasperi, F., Placi, N., et al. (2020). Bioactivity of volatile organic compounds by Aureobasidium species against gray mold of tomato and table grape. World J. Microbiol. Biotechnol. 36:171. doi: 10.1007/s11274-020-02947-7

Dias, M. P., Bastos, M. S., Xavier, V. B., Cassel, E., Astarita, L. V., and Santarem, E. R. (2017). Plant growth and resistance promoted by Streptomyces spp. in tomato. Plant Physiol. Biochem. 118, 479-493. doi: 10.1016/j.plaphy.2017.07.017

Díaz, M. A., Pereyra, M. M., Picón-Montenegro, E., Meinhardt, F., and Dib, J. R. (2020). Killer yeasts for the biological control of postharvest fungal crop diseases. Microorganisms 8:1680. doi: 10.3390/microorganisms 8111680

Fernando, W. G. D., Ramarathnam, R., Krishnamoorthy, A. S., and Savchuk, S. C. (2005). Identification and use of potential bacterial organic antifungal volatiles in biocontrol. Soil Biol. Biochem. 37, 955-964. doi: 10.1016/j. soilbio.2004.10.021

Frankowski, J., Lorito, M., Scala, F., Schmid, R., Berg, G., and Bahl, H. (2001). Purification and properties of two chitinolytic enzymes of Serratia plymuthica HRO-C48. Arch. Microbiol. 176, 421-426. doi: 10.1007/s002030100347

Fuqua, W. C., Winans, S. C., and Greenberg, E. P. (1994). Quorum sensing in bacteria: the LuxR-LuxI family of cell density-responsive transcriptional regulators. J. Bacteriol. 176, 269-275. doi: 10.1128/jb.176.2.269-275.1994

Gao, H., Li, P., Xu, X., Zeng, Q., and Guan, W. (2018). Research on volatile organic compounds from Bacillus subtilis cf-3: biocontrol effects on fruit fungal pathogens and dynamic changes during fermentation. Front. Microbiol. 9:456. doi: 10.3389/fmicb.2018.00456

Gao, Z., Zhang, B., Liu, H., Han, J., and Zhang, Y. (2017). Identification of endophytic Bacillus velezensis ZSY-1 strain and antifungal activity of its volatile compounds against Alternaria solani and Botrytis cinerea. Biol. Control 105, 27-39. doi: 10.1016/j.biocontrol.2016.11.007

Garganese, F., Sanzani, S. M., Di Rella, D., Schena, L., and Ippolito, A. (2019). Pre- and postharvest application of alternative means to control Alternaria Brown spot of citrus. Crop Prot. 121, 73-79. doi: 10.1016/j. cropro.2019.03.014

Giorgio, A., De Stradis, A., Lo Cantore, P., and Iacobellis, N. S. (2015). Biocide effects of volatile organic compounds produced by potential biocontrol rhizobacteria on Sclerotinia sclerotiorum. Front. Microbiol. 6:1056. doi: 10.3389/ fmicb.2015.01056

Go, S.-M., Park, M.-R., Kim, H.-S., Choi, W. S., and Jeong, R.-D. (2019). Antifungal effect of non-thermal atmospheric plasma and its application for control of postharvest Fusarium oxysporum decay of paprika. Food Control 98, 245-252. doi: 10.1016/j.foodcont.2018.11.028

Goswami, M., and Deka, S. (2020). Plant growth-promoting rhizobacteriaalleviators of abiotic stresses in soil: a review. Pedosphere 30, 40-61. doi: 10.1016/S1002-0160(19)60839-8

Gotor-Vila, A., Teixido, N., Di Francesco, A., Usall, J., Ugolini, L., Torres, R., et al. (2017). Antifungal effect of volatile organic compounds produced by Bacillus amyloliquefaciens CPA-8 against fruit pathogen decays of cherry. Food Microbiol. 64, 219-225. doi: 10.1016/j.fm.2017.01.006
Guevara-Avendano, E., Bejarano-Bolivar, A. A., Kiel-Martinez, A. L., Ramirez-Vazquez, M., Mendez-Bravo, A., Von Wobeser, E. A., et al. (2019). Avocado rhizobacteria emit volatile organic compounds with antifungal activity against Fusarium solani, Fusarium sp. associated with Kuroshio shot hole borer, and Colletotrichum gloeosporioides. Microbiol. Res. 219, 74-83. doi: 10.1016/j.micres.2018.11.009

Haidar, R., Roudet, J., Bonnard, O., Dufour, M. C., Corio-Costet, M. F., Fert, M., et al. (2016). Screening and modes of action of antagonistic bacteria to control the fungal pathogen Phaeomoniella chlamydospora involved in grapevine trunk diseases. Microbiol. Res. 192, 172-184. doi: 10.1016/j.micres.2016. 07.003

He, H., Song, Q., Wang, Y., and Yu, S. (2014). Phytotoxic effects of volatile organic compounds in soil water taken from a Eucalyptus urophylla plantation. Plant Soil 377, 203-215. doi: 10.1007/s11104-013-1989-1

Jin, P., Wang, H., Tan, Z., Xuan, Z., Dahar, G. Y., Li, Q. X., et al. (2020). Antifungal mechanism of bacillomycin D from Bacillus velezensis $\mathrm{HN}-2$ against Colletotrichum gloeosporioides Penz. Pestic. Biochem. Physiol. 163, 102-107. doi: 10.1016/j.pestbp.2019.11.004

Kai, M., and Piechulla, B. (2009). Plant growth promotion due to rhizobacterial volatiles an effect of CO2? FEBS Lett. 583, 3473-3477. doi: 10.1016/j. febslet.2009.09.053

Kanashiro, A. M., Akiyama, D. Y., Kupper, K. C., and Fill, T. P. (2020). Penicillium italicum: an underexplored postharvest pathogen. Front. Microbiol. 11:606852. doi: $10.3389 /$ fmicb.2020.606852

Kang, H. C., Park, Y. H., and Go, S. J. (2003). Growth inhibition of a phytopathogenic fungus, Colletotrichum species by acetic acid. Microbiol. Res. 158, 321-326. doi: 10.1078/0944-5013-00211

Khan, N., Martinez-Hidalgo, P., Ice, T. A., Maymon, M., Humm, E. A., Nejat, N., et al. (2018). Antifungal activity of Bacillus species against Fusarium and analysis of the potential mechanisms used in biocontrol. Front. Microbiol. 9:2363. doi: $10.3389 /$ fmicb. 2018.02363

Kovacs, N. (1928). Eine vereinfachte methode zum nachweis der indolbildung durch bakterien. Z. Immunitatsforsch 55, 311-315.

Larkin, J. M., and Stokes, J. L. (1967). Taxonomy of psychrophilic strains of Bacillus. J. Bacteriol. 94, 889-895. doi: 10.1128/jb.94.4.889-895.1967

Lastochkina, O., Baymiev, A., Shayahmetova, A., Garshina, D., Koryakov, I., Shpirnaya, I., et al. (2020). Effects of endophytic Bacillus subtilis and salicylic acid on postharvest diseases (Phytophthora infestans, Fusarium oxysporum) development in stored potato tubers. Plan. Theory 9:76. doi: 10.3390/ plants 9010076

Lazazzara, V., Perazzolli, M., Pertot, I., Biasioli, F., Puopolo, G., and Cappellin, L. (2017). Growth media affect the volatilome and antimicrobial activity against Phytophthora infestans in four Lysobacter type strains. Microbiol. Res. 201, 52-62. doi: 10.1016/j.micres.2017.04.015

Lee, S., Hung, R., Schink, A. E., Mauro, J., and Bennett, J. W. (2014). Arabidopsis thaliana for testing the phytotoxicity of volatile organic compounds. Plant Growth Regul. 74, 177-186. doi: 10.1007/s10725-014-9909-9

Lee, Y. J., Jeong, J. J., Jin, H., Kim, W., Jeun, Y. C., Yu, G. D., et al. (2019). In vitro and in vivo inhibitory effects of gaseous chlorine dioxide against Fusarium oxysporum f. sp. batatas isolated from stored sweetpotato: study II. Plant Pathol. J. 35, 437-444. doi: 10.5423/PPJ.OA.04.2019.0078

Lemfack, M. C., Gohlke, B. O., Toguem, S. M. T., Preissner, S., Piechulla, B., and Preissner, R. (2018). mVOC 2.0: a database of microbial volatiles. Nucleic Acids Res. 46, D1261-D1265. doi: 10.1093/nar/gkx1016

Li, Q., Ning, P., Zheng, L., Huang, J., Li, G., and Hsiang, T. (2010). Fumigant activity of volatiles of Streptomyces globisporus jk-1 against Penicillium italicum on Citrus microcarpa. Postharvest Biol. Technol. 58, 157-165. doi: 10.1016/j. postharvbio.2010.06.003

Lim, S. M., Yoon, M. Y., Choi, G. J., Choi, Y. H., Jang, K. S., Shin, T. S., et al. (2017). Diffusible and volatile antifungal compounds produced by an antagonistic Bacillus velezensis g341 against various phytopathogenic fungi. Plant Pathol. J. 33, 488-498. doi: 10.5423/PPJ.OA.04.2017.0073

Liu, C., Cui, Z., Yan, X., Qi, Z., Ji, M., and Li, X. (2016). Synthesis, fungicidal activity and mode of action of 4-phenyl-6-trifluoromethyl-2-aminopyrimidines against Botrytis cinerea. Molecules 21:828. doi: 10.3390/molecules21070828

Logan, N. A., Berge, O., Bishop, A. H., Busse, H.-J., De Vos, P., Fritze, D., et al. (2009). Proposed minimal standards for describing new taxa of aerobic, endospore-forming bacteria. Int. J. Syst. Evol. Microbiol. 59, 2114-2121. doi: 10.1099/ijs.0.013649-0 
Mari, M., Bautista-Baños, S., and Sivakumar, D. (2016). Decay control in the postharvest system: role of microbial and plant volatile organic compounds. Postharvest Biol. Technol. 122, 70-81. doi: 10.1016/j. postharvbio.2016.04.014

Marquez-Villavicencio Mdel, P., Weber, B., Witherell, R. A., Willis, D. K., and Charkowski, A. O. (2011). The 3-hydroxy-2-butanone pathway is required for Pectobacterium carotovorum pathogenesis. PLoS One 6:e22974. doi: 10.1371/ journal.pone.0022974

Martini, C., and Mari, M. (2014). "Monilinia fructicola, Monilinia laxa (Monilinia rot, Brown rot)" in Postharvest Decay. ed. S. Bautista-Baños (Centro de Desarrollo de, Productos Bióticos, Yautepec Morelos, Mexico: Academic Press), 233-265.

Massawe, V. C., Hanif, A., Farzand, A., Mburu, D. K., Ochola, S. O., Wu, L., et al. (2018). Volatile compounds of endophytic Bacillus spp. have biocontrol activity against Sclerotinia sclerotiorum. Phytopathology 108, 1373-1385. doi: 10.1094/PHYTO-04-18-0118-R

Medina-Romero, Y. M., Roque-Flores, G., and Macias-Rubalcava, M. L. (2017). Volatile organic compounds from endophytic fungi as innovative postharvest control of Fusarium oxysporum in cherry tomato fruits. Appl. Microbiol. Biotechnol. 101, 8209-8222. doi: 10.1007/s00253-017-8542-8

Mercier, J., and Smilanick, J. L. (2005). Control of green mold and sour rot of stored lemon by biofumigation with Muscodor albus. Biol. Control 32, 401-407. doi: 10.1016/j.biocontrol.2004.12.002

Momma, N., Yamamoto, K., Simandi, P., and Shishido, M. (2006). Role of organic acids in the mechanisms of biological soil disinfestation (BSD). J. Gen. Plant Pathol. 72, 247-252. doi: 10.1007/s10327-006-0274-Z

Montaño, A., Cortés-Delgado, A., Sánchez, A. H., and Ruiz-Barba, J. L. (2021). Production of volatile compounds by wild-type yeasts in a natural olive-derived culture medium. Food Microbiol. 98:103788. doi: 10.1016/j.fm.2021.103788

Nasir, M., Bean, H. D., Smolinska, A., Rees, C. A., Zemanick, E. T., and Hill, J. E. (2018). Volatile molecules from bronchoalveolar lavage fluid can 'rule-in' Pseudomonas aeruginosa and 'rule-out' Staphylococcus aureus infections in cystic fibrosis patients. Sci. Rep. 8:826. doi: 10.1038/s41598-017-18491-8

Obi, V. I., Barriuso, J. J., and Gogorcena, Y. (2018). Effects of $\mathrm{pH}$ and titratable acidity on the growth and development of Monilinia laxa (Aderh. \& Ruhl.) in vitro and in vivo. Eur. J. Plant Pathol. 151, 781-790. doi: 10.1007/ s10658-017-1413-4

Ossowicki, A., Jafra, S., and Garbeva, P. (2017). The antimicrobial volatile power of the rhizospheric isolate Pseudomonas donghuensis P482. PLoS One 12:e0174362. doi: 10.1371/journal.pone.0174362

Parafati, L., Vitale, A., Restuccia, C., and Cirvilleri, G. (2017). Performance evaluation of volatile organic compounds by antagonistic yeasts immobilized on hydrogel spheres against gray, green and blue postharvest decays. Food Microbiol. 63, 191-198. doi: 10.1016/j.fm.2016.11.021

Poveda, J. (2020). Use of plant-defense hormones against pathogen-diseases of postharvest fresh produce. Physiol. Mol. Plant Pathol. 111:101521. doi: 10.1016/j.pmpp.2020.101521

Poveda, J. (2021). Beneficial effects of microbial volatile organic compounds (MVOCs) in plants. Appl. Soil Ecol. 168:104118. doi: 10.1016/j.apsoil. 2021.104118

Poveda, J., Eugui, D., and Velasco, P. (2020). Natural control of plant pathogens through glucosinolates: an effective strategy against fungi and oomycetes. Phytochem. Rev. 19, 1045-1059. doi: 10.1007/s11101-020-09699-0

Qin, X., Xiao, H., Cheng, X., Zhou, H., and Si, L. (2017). Hanseniaspora uvarum prolongs shelf life of strawberry via volatile production. Food Microbiol. 63, 205-212. doi: 10.1016/j.fm.2016.11.005

Rajaofera, M. J. N., Wang, Y., Dahar, G. Y., Jin, P., Fan, L., Xu, L., et al. (2019). Volatile organic compounds of Bacillus atrophaeus HAB-5 inhibit the growth of Colletotrichum gloeosporioides. Pestic. Biochem. Physiol. 156, 170-176. doi: 10.1016/j.pestbp.2019.02.019

Rashmi, B., Bharti, S. K., Gogoi, M., Devi, S., and Anita, G. S. (2017). Antibiotic resistance: role of fruits and vegetables in the food basket. Int. J. Pure Appl. Biosci. 5, 169-173. doi: 10.18782/2320-7051.5327

Reverchon, F., Garcia-Quiroz, W., Guevara-Avendano, E., Solis-Garcia, I. A., Ferrera-Rodriguez, O., and Lorea-Hernandez, F. (2019). Antifungal potential of Lauraceae rhizobacteria from a tropical montane cloud forest against Fusarium spp. Braz. J. Microbiol. 50, 583-592. doi: 10.1007/s42770-019-00094-2

Rodriguez, M., Marin, A., Torres, M., Bejar, V., Campos, M., and Sampedro, I. (2018). Aphicidal activity of surfactants produced by Bacillus atrophaeus L193. Front. Microbiol. 9:3114. doi: 10.3389/fmicb.2018.03114
Rodriguez, M., Reina, J. C., Bejar, V., and Llamas, I. (2020a). Psychrobacillus vulpis sp. nov., a new species isolated from faeces of a red fox in Spain. Int. J. Syst. Evol. Microbiol. 70, 882-888. doi: 10.1099/ijsem.0.003840

Rodriguez, M., Torres, M., Blanco, L., Bejar, V., Sampedro, I., and Llamas, I. (2020b). Plant growth-promoting activity and quorum quenching-mediated biocontrol of bacterial phytopathogens by Pseudomonas segetis strain P6. Sci. Rep. 10:4121. doi: 10.1038/s41598-020-61084-1

Rungjindamai, N., Jeffries, P., and Xu, X.-M. (2014). Epidemiology and management of brown rot on stone fruit caused by Monilinia laxa. Eur. J. Plant Pathol. 140, 1-17. doi: 10.1007/s10658-014-0452-3

Ryu, C. M., Farag, M. A., Hu, C. H., Reddy, M. S., Kloepper, J. W., and Pare, P. W. (2004). Bacterial volatiles induce systemic resistance in Arabidopsis. Plant Physiol. 134, 1017-1026. doi: 10.1104/pp.103.026583

Sadfi-Zouaoui, N., Essghaier, B., Hajlaoui, M. R., Fardeau, M. L., Cayaol, J. L., Ollivier, B., et al. (2008). Ability of moderately halophilic bacteria to control grey mould disease on tomato fruits. J. Phytopathol. 156, 42-52.

Sasser, M. (1990). Identification of Bacteria by Gas Chromatography of Cellular Fatty Acids. Newark, DE: MIDI Inc.

Schmidt, R., Cordovez, V., De Boer, W., Raaijmakers, J., and Garbeva, P. (2015). Volatile affairs in microbial interactions. ISME J. 9, 2329-2335. doi: 10.1038/ ismej.2015.42

Schneider, C. A., Rasband, W. S., and Eliceiri, K. W. (2012). NIH Image to ImageJ: 25 years of image analysis. Nat. Methods 9, 671-675. doi: 10.1038/ nmeth.2089

Shi, X.-C., Wang, S.-Y., Duan, X.-C., Wang, Y.-Z., Liu, F.-Q., and Laborda, P. (2021). Biocontrol strategies for the management of Colletotrichum species in postharvest fruits. Crop Prot. 141:105454. doi: 10.1016/j.cropro.2020.105454

Sierra, G. (1957). A simple method for the detection of lipolytic activity of micro-organisms and some observations on the influence of the contact between cells and fatty substrates. Antonie Van Leeuwenhoek 23, 15-22. doi: 10.1007/BF02545855

Syed-Ab-Rahman, S. F., Carvalhais, L. C., Chua, E. T., Chung, F. Y., Moyle, P. M., Eltanahy, E. G., et al. (2019). Soil bacterial diffusible and volatile organic compounds inhibit Phytophthora capsici and promote plant growth. Sci. Total Environ. 692, 267-280. doi: 10.1016/j.scitotenv.2019.07.061

Tahir, H. A., Gu, Q., Wu, H., Niu, Y., Huo, R., and Gao, X. (2017). Bacillus volatiles adversely affect the physiology and ultra-structure of Ralstonia solanacearum and induce systemic resistance in tobacco against bacterial wilt. Sci. Rep. 7:40481. doi: 10.1038/srep40481

Toffano, L., Fialho, M. B., and Pascholati, S. F. (2017). Potential of fumigation of orange fruits with volatile organic compounds produced by Saccharomyces cerevisiae to control citrus black spot disease at postharvest. Biol. Control 108, 77-82. doi: 10.1016/j.biocontrol.2017.02.009

Toral, L., Rodríguez, M., Béjar, V., and Sampedro, I. (2018). Antifungal activity of lipopeptides from Bacillus methylotrophicus XT1 CECT 8661 against Botrytis cinerea. Front. Microbiol. 9:1315. doi: 10.3389/fmicb.2018.01315

Tozlu, E., Kotan, M. Ş., Tekiner, N., Dikbaş, N., and Kotan, R. (2018). Biological control of postharvest spoilage in fresh mandarins (Citrus reticulata Blanco) fruits using bacteria during storage. Erwerbs-obstbau 61, 157-164. doi: 10.1007/ s10341-018-0412-8

Vega, C., Rodriguez, M., Llamas, I., Bejar, V., and Sampedro, I. (2019). Silencing of phytopathogen communication by the halotolerant PGPR Staphylococcus equorum strain EN21. Microorganisms 8:42. doi: 10.3390/ microorganisms 8010042

Wenke, K., Kai, M., and Piechulla, B. (2010). Belowground volatiles facilitate interactions between plant roots and soil organisms. Planta 231, 499-506. doi: 10.1007/s00425-009-1076-2

Wu, Y., Zhou, J., Li, C., and Ma, Y. (2019). Antifungal and plant growth promotion activity of volatile organic compounds produced by Bacillus amyloliquefaciens. Microbiology 8:e00813. doi: 10.1002/mbo3.813

Yu, L., Qiao, N., Zhao, J., Zhang, H., Tian, F., Zhai, Q., et al. (2020). Postharvest control of Penicillium expansum in fruits: a review. Food Biosci. 36:100633. doi: 10.1016/j.fbio.2020.100633

Yuan, J., Raza, W., Shen, Q., and Huang, Q. (2012). Antifungal activity of Bacillus amyloliquefaciens NJN-6 volatile compounds against Fusarium oxysporum f. sp. cubense. Appl. Environ. Microbiol. 78, 5942-5944. doi: 10.1128/AEM.01357-12

Zhang, H., Godana, E. A., Sui, Y., Yang, Q., Zhang, X., and Zhao, L. (2020a). Biological control as an alternative to synthetic fungicides for the management 
of grey and blue mould diseases of table grapes: a review. Crit. Rev. Microbiol. 46, 450-462. doi: 10.1080/1040841X.2020.1794793

Zhang, D., Yu, S., Yang, Y., Zhang, J., Zhao, D., Pan, Y., et al. (2020b). Antifungal effects of volatiles produced by Bacillus subtilis against Alternaria solani in potato. Front. Microbiol. 11:1196. doi: 10.3389/fmicb.2020.01196

Zhao, S., Guo, Y., Wang, Q., Luo, H., He, C., and An, B. (2020). Expression of flagellin at yeast surface increases biocontrol efficiency of yeast cells against postharvest disease of tomato caused by Botrytis cinerea. Postharvest Biol. Technol. 162:111112. doi: 10.1016/j.postharvbio.2019. 111112

Zheng, L., Situ, J.-J., Zhu, Q.-F., Xi, P.-G., Zheng, Y., Liu, H.-X., et al. (2019). Identification of volatile organic compounds for the biocontrol of postharvest litchi fruit pathogen Peronophythora litchii. Postharvest Biol. Technol. 155, 37-46. doi: 10.1016/j.postharvbio.2019.05.009

Zhou, M., Li, P., Wu, S., Zhao, P., and Gao, H. (2019). Bacillus subtilis CF-3 volatile organic compounds inhibit Monilinia fructicola growth in peach fruit. Front. Microbiol. 10:1804. doi: 10.3389/fmicb.2019.01804
Conflict of Interest: The authors declare that the research was conducted in the absence of any commercial or financial relationships that could be construed as a potential conflict of interest.

Publisher's Note: All claims expressed in this article are solely those of the authors and do not necessarily represent those of their affiliated organizations, or those of the publisher, the editors and the reviewers. Any product that may be evaluated in this article, or claim that may be made by its manufacturer, is not guaranteed or endorsed by the publisher.

Copyright (c) 2021 Toral, Rodríguez, Martínez-Checa, Montaño, Cortés-Delgado, Smolinska, Llamas and Sampedro. This is an open-access article distributed under the terms of the Creative Commons Attribution License (CC BY). The use, distribution or reproduction in other forums is permitted, provided the original author(s) and the copyright owner(s) are credited and that the original publication in this journal is cited, in accordance with accepted academic practice. No use, distribution or reproduction is permitted which does not comply with these terms. 